\title{
Improving Quality of Care and Guideline Adherence for Asthma Through a Group Self-Assessment Module
}

\author{
Kurt Elward, MD, MPH, Brenna Blackburn, MPH, Lars E. Peterson, MD, PhD, \\ Mark Greenawald, MD, and Michael D. Hagen, MD
}

Background: The quality of care for asthma remains suboptimal. Compliance with guidelines remains low, but improved adherence to guidelines may increase the quality of care. but. We conducted a trial to determine whether group Self-Assessment Module (SAM) activities led by a facilitator and conducted as part of Maintenance of Certification for Family Physicians (MC-FP) would increase knowledge of and adherence to asthma guidelines.

Methods: Participating physicians completed audits of the charts of patients with asthma before and 6 months after a group SAM. Surveys of physicians' knowledge of asthma guidelines were administered immediately before, immediately after, and 6 months after the group SAM. We tested for differences in knowledge of and adherence to guidelines before and after the SAM using $\chi^{2}$ and $t$ tests.

Results: Thirty-eight physicians in Virginia completed the SAM and had complete data. Participants completed more MC-FP activities than other physicians but were comparable in other characteristics. Except for prescribing controller medications for persistent asthma, all other quality measures significantly improved 6 months after the group SAM. Diagnosis by severity improved from $48.3 \%$ to $80.2 \%$, and the use of action plans increased from $8.1 \%$ to $54.1 \%$. Physicians' knowledge of guidelines improved immediately after the SAM and was sustained at 6 months. Increased knowledge translated into clinical skills: $30 \%$ of participants reported comfort with assessing control after the SAM, which increased to $97.5 \% 6$ months after the SAM.

Conclusions: Group SAMs may be an effective method to increase physicians' knowledge of and adherence to clinical guidelines. (J Am Board Fam Med 2014;27:391-398.)

Keywords: Asthma, Certification, Educational Assessment, Guideline Adherence

Asthma continues to represent a major cause of emergency department visits and excess hospitalizations. ${ }^{1,2}$ Appropriate therapy and management of triggers of asthma can greatly ameliorate these adverse outcomes, as well as morbidity and mortality. ${ }^{3}$ To promote appropriate asthma management,

This article was externally peer reviewed.

Submitted 20 August 2013; revised 7 February 2014; accepted 10 February 2014.

From Family Medicine of Albemarle, Charlottesville, VA (KE); Department of Family Medicine and Population Health (KE), the Virginia Commonwealth University, Richmond; The American Board of Family Medicine, Lexington, KY (BB, LEP, MDH); the Department of Family and Community Medicine, University of Kentucky College of Medicine, Lexington (LEP, MDH); and the Department of Family and Community Medicine, Virginia Tech Carilion School of Medicine and Research Institute, Roanoke (MG). the National Heart, Lung and Blood Institute (NHLBI) periodically produces guidelines that summarize current evidence and outline optimal management strategies. ${ }^{3-5}$

Dissemination of guidelines has been a major challenge, and multiple studies have shown lack of awareness and implementation of guidelines across

Funding: This study was supported in part by a contract from the National Heart, Lung, and Blood Institute's National Asthma Control Initiative Strategic Partnership Engagement

Program (administered through the Academy for Educational Development).

Conflict of interest: LEP and MDH are full-time employees of the American Board of Family Medicine. BB was a fulltime employee of the American Board of Family Medicine when the original manuscript was submitted.

Corresponding author: Michael Hagen, MD. MPH, American Board of Family Medicine, 1648 McGrathiana Parkway, Suite 550, Lexington, KY 40511-1247 (E-mail: hagen@theabfm.org). 
the clinical spectrum. ${ }^{6}$ Despite evidence-based guidelines being available for $>20$ years and concomitant research demonstrating improved outcomes associated with guideline adherence, health care providers do not consistently follow asthma guideline recommendations. ${ }^{7-9}$ In fact, available data continue to indicate less-than-optimal care for asthma in primary care. For example, despite its central importance in asthma management, ${ }^{3}$ asthma control is not appropriately evaluated for many patients, ${ }^{10-13}$ and minority children are half as likely as white children to receive inhaled steroids and other standard elements of asthma treatment. ${ }^{14-16}$ In addition, when patients are properly assessed, as few as $30 \%$ of persistent asthmatics have prescribed controller medication, and the use of action plans remains low. ${ }^{7-9,17}$

Following the development of the 2007 Expert Panel Report 3 (EPR-3), the NHLBI convened the Guidelines Implementation Panel to develop recommendations for accomplishing greater utilization of the guidelines. ${ }^{18}$ The Guidelines Implementation Panel report focused on 6 key messages from EPR-3: (1) the use of controller medications (eg, inhaled corticosteroids) for persistent asthma; (2) written asthma action plans; (3) standardized assessment of asthma severity; (4) standardized assessment of level of control; (5) scheduled periodic follow-up visits; and (6) control of asthma triggers (eg, mold and other allergens). ${ }^{18}$ To encourage innovative programs for promoting these recommendations, the NHLBI also created the National Asthma Control Initiative (NACI) as a vehicle for funding demonstration projects that could explore best practices for disseminating these management strategies among patients, health care professionals, organizations, and leaders. ${ }^{19}$

The American Board of Family Medicine (ABFM) implemented its Maintenance of Certification for Family Physicians (MC-FP) program in 2004..$^{20}$ Part II of the MC-FP consists of self-assessment modules (SAMs) that contain 2 parts: a 60 -item knowledge assessment, with references and critiques, and a simulation that focuses on managing a patient with the module's clinical focus (eg, asthma.) In 2005, the ABFM deployed an asthma SAM, which contained content that largely reflected the material presented in the 1997 NHLBI asthma guideline and the associated 2002 update. ${ }^{4,5}$ Following the release of the 2007 EPR-3 guideline, the ABFM revised the asthma SAM content to support these new recommendations. Over the next several years, the ABFM noted increased use of asthma simulations of particular EPR-3-recommended management strategies (eg, written action plans and use of controller medications for persistent asthma). ${ }^{21}$

On the basis of this encouraging pattern of guideline-recommended behaviors, ABFM responded to the NACI call for proposals for organizations to become NACI Strategic Partners ${ }^{22}$ in promoting the EPR-3 key asthma management messages. For the proposal, the ABFM (MDH) partnered with investigators from Virginia Commonwealth University (KE) and the Virginia Tech Carilion School of Medicine and Research Institute (MG). Based on the previous results with EPR-3 emphases in the asthma SAM, in our response we proposed further augmentation of the EPR-3 key messages through a process of delivery via a group SAM. The objectives of this study were to evaluate the effectiveness of a facilitator-led group SAM for guideline dissemination and adherence to guidelines in practice.

\section{Methods}

We constructed an experimental design with 2 arms: (1) a group of physicians engaged in group SAM activities that were conducted by trained facilitators who emphasized the 6 key messages of the EPR-3 guideline (intervention group) and (2) a control arm of physicians taking the asthma SAM in the usual online individual format. To identify potential control participants, the ABFM searched SAM completion data to identify diplomates in Florida, Colorado, Oklahoma, and Virginia who had not previously completed the asthma SAM. The identified diplomates were invited via E-mail (all current ABFM diplomates have E-mail addresses on record with the ABFM) to participate in the study. The invitation included a description of the purpose and study design as well as indication of incentive payments available to participants. The ABFM has created 15 SAMs for use in the MC-FP process; historically, only approximately $11 \%$ of diplomates have chosen the asthma SAM for completion of their part MC-FP Part II requirements (ABFM internal weekly MC-FP report, available upon request.)

SAMs are typically conducted as an individual learning exercise via the ABFM website (www.theabfm. org). In this study we implemented a standardized 
curriculum developed by 2 of the authors (KE and MG). They identified facilitators to conduct group SAM activities at state Academy of Family Physician chapter meetings in Virginia, Florida, Colorado, and Oklahoma. The facilitator training focused on content of the asthma SAM that was revised to further emphasize the 6 key EPR-3 messages: use of inhaled corticosteroids for control of persistent asthma; use of written asthma action plans; assessment of asthma severity; assessment and monitoring of asthma control; scheduled follow-up visits; and control of environmental triggers. The intervention was provided during 6 sessions at meetings of the 4 state chapters in the fall of 2011 and used a facilitated group learning process in which the participants review and discuss the SAM material together. This process allowed major teaching points to be highlighted, unclear areas to be clarified, and the most important material to be summarized. Participants in the group and control processes completed surveys regarding their knowledge of guidelines and other aspects of asthma care before, immediately after, and 6 months after completing the SAM. To assess effects on the quality of care and adherence to the 6 key messages from the EPR-3 guidelines in practice, participants completed chart audits of 15 patients before the SAM and 6 months after completing the SAM.

Physicians were included in the analysis if they completed the entire process and all surveys and chart audits were available for analysis. This included a consent form, before and after chart audits, and 3 surveys (before, immediately after, and 6 months after the SAM). All the physicians (except one) who had complete data available for analysis were from Virginia. We excluded the one person not from Virginia to have a more cohesive sample. With this knowledge, we compared the demographics of the diplomates in the intervention group to all other diplomates from Virginia in the ABFM database who have taken the certification or recertification examination since 2000. Despite the targeted recruiting (including financial incentives) for control participants, as described above, we did not achieve sufficient responses to support inclusion of the originally proposed control arm in the final analysis.

Each chart audit (before and 6 months after the SAM) contained 15 patients and asked about the 6 key messages for each patient: (1) Is the asthmatic diagnosed according to National Asthma Education and Prevention Program criteria? (2) Was an asthma control test or asthma therapy assessment questionnaire used at the last asthma visit? (3) Was there a planned asthma visit in the past year? (4) Is there an asthma action plan in the chart? (5) Was a controller medication prescribed for persistent asthmatics? and (6) If there was a controller medication prescribed, was it an inhaled corticosteroid (ICS), leukotriene agonist, or a combination?

The formatting of the surveys before, immediately after, and 6 months after the SAM was slightly different, and some items that were eliminated because of feedback about their wording. These items were not included in the analysis. There were variations in the 6-month survey because of specific issues that were addressed in the different group SAM sessions. For analysis we combined all similar questions from these 6-month surveys. The majority of questions used a modified Likert scale. For analytic purposes, we collapsed the responses to each Likert-style question into 2 categories: strongly agree/agree or strongly disagree/disagree, or never/ rarely a problem or likely/very likely a problem versus other. To gauge the possible effect of the SAM on specific areas of asthma care, surveys after the SAM asked about changes made in the physician's practice. Survey instruments were pretested by focus groups conducted by the Kentucky Ambulatory Network.

For the questions that were comparable across all 3 surveys, $\chi^{2}$ tests were used to determine statistical significance over time. Statistical significance was measured at $P<.05$. Statistical analysis was done using SAS software version 9.3 (SAS, Inc., Cary, NC). The protocol received approval as an exempt study by the University of Kentucky Medical Institutional Review Board (IRB no. 11-0077$\mathrm{X} 2 \mathrm{~B}$, on file with the ABFM).

\section{Results}

Of the 114 physicians who started in the intervention group, 39 (34.2\%) completed the process with all data available for analysis. The 114 physicians were from Virginia (54.4\%), Oklahoma (22.8\%), Colorado (18.4\%), and Florida (4.4\%). Of those who completed the entire study protocol, 38 were from Virginia and one was from Florida. Compared with all the Virginia family physicians in the ABFM database, the intervention group completed 
more total MC-FP modules and had a higher score on the most recent primary certification examination. Although not statistically significant, physicians in the intervention were more likely to be women, an MD versus DO, and currently be board certified (Table 1).

Physician adherence to asthma care guidelines improved after participating in the group SAM (Table 2). Having an asthma action plan in the chart markedly increased from $8.1 \%$ to $54.1 \%$ of patients, and using an asthma control test or asthma therapy assessment questionnaire increased from $11.2 \%$ to $53.3 \%$. The severity of asthma based on National Asthma Education and Prevention Program criteria was reported for nearly half of patient visits before the group SAM and for $80.2 \%$ of visits after the group SAM. Prescribing a controller inhaler medication increased significantly after the group SAM; the increase was seen exclusively for ICS at the expense of either an leukotriene agonist or a combination ICS/long-acting $\beta$-antagonist.

Physicians' knowledge of the EPR-3 guidelines improved after the group SAM and was largely sustained in the 6-month survey (Table 3). All respondents immediately and 6 months after the SAM agreed that ICSs are recommended for all persistent asthmatics, consistent with the increase in the prescription of ICSs as abstracted during chart review. Physicians' comfort with assessing

Table 1. Personal Characteristics of Group Self-Assessment Module (SAM) Participants from Virginia Versus All American Board of Family Medicine Physicians

\begin{tabular}{lcc}
\hline Characteristics & $\begin{array}{c}\text { Group Asthma } \\
\text { SAM Participants } \\
(\mathrm{n}=38)\end{array}$ & $\begin{array}{c}\text { Virginia Family } \\
\text { Physicians } \\
(\mathrm{n}=2812)\end{array}$ \\
\hline Age (years) & $50.9(7.7)$ & $50.3(10.5)$ \\
Years practicing & $19.7(8.7)$ & $17.9(11.1)$ \\
Total MC-FP modules & $5.5(2.3)$ & $4.4(3.1)^{*}$ \\
$\quad$ completed & $3.9(1.9)$ & $3.6(2.4)$ \\
SAMs completed & $1.7(0.9)$ & $0.8(0.9)^{*}$ \\
PPMs completed & $557.9(87.0)$ & $512.5(93.1)^{*}$ \\
Last primary exam score & 55.3 & 62.1 \\
Male sex & 97.4 & 93.5 \\
MD degree & 97.4 & 90.3 \\
Currently board certified & &
\end{tabular}

Data are means (standard deviations) or percentages. ${ }^{*} P<.05$.

MC-FP, Maintenance of Certification for Family Physicians; PPM, Performance in the Practice of Medicine module.
Table 2. Physicians' Abstracted Adherence to Asthma Guidelines Before and 6 Months After a Group Self-Assessment Module (SAM)

\begin{tabular}{lrc}
\hline & $\begin{array}{r}\text { Before } \\
\text { SAM }\end{array}$ & $\begin{array}{c}\text { 6 Months } \\
\text { after SAM }\end{array}$ \\
\hline Diagnosed according to NAEPP criteria & 48.3 & $80.2^{*}$ \\
ACT or ATAQ used at last asthma visit & 11.2 & $53.3^{*}$ \\
Planned asthma visit in the past year & 50.7 & $75.0^{*}$ \\
Asthma action plan in chart & 8.1 & $54.1^{*}$ \\
Controller medication prescribed for & 75.7 & 80.4 \\
$\quad$ persistent asthma & 32.1 & $48.7^{*}$ \\
ICS & 29.5 & 28.1 \\
LTA & 58.5 & 56.3 \\
ICS/LABA combination & & \\
\hline
\end{tabular}

${ }^{*} P<.05$.

ACT, Asthma Control Test; ATAQ, Asthma Therapy Assessment Questionnaire; ICS, inhaled corticosteroid; LABA, longacting $\beta$-agonist; LTA, leukotriene agonist; NAEPP, National Asthma Education and Prevention Program.

control improved nearly $30 \%$ from the survey before to that immediately after the SAM and further increased to $97.8 \%$ at 6 months. In contrast, agreement on assessing severity and the classification system improved dramatically from before to immediately after the SAM but were reduced at 6 months.

In the survey before the SAM, $7.9 \%$ of physicians reported few or no problems with using action plans (Table 4). Immediately after the SAM and at 6 months, $94.7 \%$ and $75.0 \%$, respectively, reported the SAM helped them feel more confident in using action plans (Table 5). Despite a decrease in confidence with action plans, the reported increase in written action plans in the chart increased from $8.1 \%$ to $54.1 \%$.

The group SAM process improved physicians' confidence in many areas (Table 5) when compared with their reported challenges in providing asthma care (Table 4). For example, only a third of physicians reported that assessment of severity as never or rarely a problem before the SAM. All these physicians reported a boost in confidence in their ability to assess severity after the SAM: $>90 \%$ reported sustained confidence at 6 months. This confidence carried over to both reported likelihood of assessing severity based on the EPR-3 criteria (Table 5) and documented patient assessments (Table 2).

We found large agreement between the physician-reported likelihood of adherence to the guide- 
Table 3. Physician-Reported Assessment and Perceptions of Asthma Treatment Guidelines Before, Immediately After, and 6 Months After a Group Self-Assessment Module (SAM)*

\begin{tabular}{|c|c|c|c|c|}
\hline Statement & Agreement & $\begin{array}{l}\text { Before SAM } \\
(\mathrm{n}=39)\end{array}$ & $\begin{array}{l}\text { Immediately after } \\
\text { SAM }(\mathrm{n}=39)\end{array}$ & $\begin{array}{l}6 \text { Months after } \\
\text { SAM }(\mathrm{n}=32)\end{array}$ \\
\hline Inhaled steroids are recommended for all persistent asthmatics & Agree & 89.5 & 100 & $100^{\dagger}$ \\
\hline The approach to severity assessment is clear for me. & Agree & 55.3 & 100 & $86.2^{\dagger}$ \\
\hline $\begin{array}{l}\text { There are four steps in the asthma classification system: mild } \\
\text { intermittent, moderate intermittent, moderate persistent } \\
\text { and severe persistent. }\end{array}$ & Disagree & 47.4 & 84.2 & $59.4^{\dagger}$ \\
\hline $\begin{array}{l}\text { I feel comfortable with my ability to assess control as } \\
\text { recommended in the guidelines. }\end{array}$ & Agree & 47.4 & 82.1 & $97.8^{\dagger}$ \\
\hline
\end{tabular}

*Before SAM indicates the initial assessment of EPR-3 guidelines. Immediately after SAM and 6 months after SAM indicate questions related to perceptions of the NHLBI asthma guideline recommendations and format.

${ }^{\dagger} P<.05$.

EPR-3, Expert Panel Report 3; NHLBI, National Heart, Lung, and Blood Institute.

lines immediately and 6 months after the SAM (Table 5) and chart-abstracted adherence 6 months after the SAM. All of the physicians agreed that ICS was the preferred controller medication both immediately and 6 months after the SAM. Nearly half of the patients were taking an ICS alone after 6 months, and slightly more than half were taking an ICS/long-acting $\beta$-agonist combination (Table 2). Similarly, initial confidence in providing planned visits translated into both the reported likelihood and documented performance of these important asthma care services.

Table 4. Physician-Reported Challenges in Delivering Asthma Care Before Participation in the Group SelfAssessment Module (SAM) $(\mathrm{n}=38)$

\begin{tabular}{lc}
\hline $\begin{array}{l}\text { Major Challenges That Are Never or Rarely } \\
\text { a Problem }\end{array}$ & $\begin{array}{c}\text { Respondents } \\
(\%)\end{array}$ \\
\hline Assessment of severity & 31.6 \\
Assessment of control (eg, using ACT or & 18.4 \\
ATAQ) & 23.7 \\
Planned visits & 7.9 \\
Use of action plans & 18.4 \\
Environmental assessment & 81.6 \\
Use of inhaled steroids for persistent asthma & 62.5 \\
Making the diagnosis & 42.1 \\
Allergy evaluation & 21.0 \\
Time constraints for evaluation & 39.5 \\
Treatment grids & 63.2 \\
Referral criteria & \\
\hline${ }^{*}$ A .05. & \\
ACT, Asthma Control Test; ATAQ, Asthma Therapy Assess- \\
ment Questionnaire.
\end{tabular}

\section{Discussion}

Our study demonstrated that a facilitator-led group ABFM self-assessment activity can lead to meaningful improvements in both the quality of asthma care provided and adherence to guidelines. Physician performance improved for nearly all the key interventions recommended in the EPR-3 guidelines. Previous research suggests that providing abbreviated, focused guidelines can improve patient outcomes. ${ }^{23}$ Our NACI project seems to corroborate that insight and indicates that the Maintenance of Certification (MOC) paradigm can serve as a vehicle for delivering focused guideline-related content.

A number of authors have expressed concern regarding the value (real or perceived) of specialty board MOC programs. ${ }^{24,25} \mathrm{~A}$ growing body of literature, however, supports the value of MOC activities in improving physician performance and patient outcomes. ${ }^{26,27}$ Our results suggest an additional purpose to MOC: the promotion and dissemination of evidence-based guideline recommendations. The presenters of the group SAM intervention in this study (MG and $\mathrm{KE}$ ) noted that many questions from the family physicians during the sessions focused on specific examples of how to implement the guidelines into real practice. Future guidelines may need to provide examples of use or online tutorials/practice vignettes to facilitate implementation in practice. In addition, access to the supporting literature is limited because of subscription fees. Developers of future guidelines should consider making key articles available free. The participants seemed to be 


\begin{tabular}{|c|c|c|c|}
\hline & Agreement & $\begin{array}{l}\text { Immediately after } \\
\text { SAM }(\mathrm{n}=38)\end{array}$ & $\begin{array}{l}6 \text { Months after } \\
\text { SAM }(\mathrm{n}=32)\end{array}$ \\
\hline \multicolumn{4}{|l|}{ The SAM helped me feel more confident in this area. } \\
\hline Assessment of severity & Agree/strongly agree & 100 & 93.8 \\
\hline Assessment of control (eg, using ACT or ATAQ) & Agree/strongly agree & 94.7 & 96.9 \\
\hline Planned visits & Agree/strongly agree & 100 & 90.6 \\
\hline Use of action plans & Agree/strongly agree & 94.7 & $75.0^{*}$ \\
\hline Environmental assessment & Agree/strongly agree & 94.7 & 80.7 \\
\hline Use of inhaled steroids for persistent asthma & Agree/strongly agree & 100 & 100 \\
\hline Making the diagnosis & Agree/strongly agree & 92.1 & 93.8 \\
\hline Allergy evaluation & Agree/strongly agree & 96.8 & 71.0 \\
\hline Time constraints for evaluation & Agree/strongly agree & 67.6 & 65.6 \\
\hline Treatment grids & Agree/strongly agree & 96.8 & 84.4 \\
\hline At the end of this SAM, how likely were you to: & & $\begin{array}{l}\text { Immediately after } \\
\text { SAM }(\mathrm{n}=38)\end{array}$ & $\begin{array}{l}6 \text { Months after } \\
\text { SAM }(\mathrm{n}=25)\end{array}$ \\
\hline $\begin{array}{l}\text { Use inhaled corticosteroids as the preferred controller agent } \\
\text { for treatment }\end{array}$ & Likely/very likely & 100 & 100 \\
\hline Begin planned asthma visits for patients with persistent asthma & Likely/very likely & 100 & 92.0 \\
\hline Assess severity based on EPR- 3 criteria & Likely/very likely & 92.1 & $96.0^{*}$ \\
\hline Assess control using the ACT or ATAQ & Likely/very likely & 94.7 & $88.0^{*}$ \\
\hline Refer for allergy evaluation & Likely/very likely & 84.2 & 80.0 \\
\hline Seek an environmental assessment for persistent asthmatics & Likely/very likely & 89.5 & 84.0 \\
\hline
\end{tabular}

${ }^{*} P<.05$.

ACT, Asthma Control Test; ATAQ, Asthma Therapy Assessment Questionnaire; EPR-3, Expert Panel Report 3.

challenged by the sheer volume of the guidelines and the lack of a paradigm or suggested practice plan tailored for primary care. The interactive environment of the group SAMs facilitated this discussion, but online support and interchange could be developed in the future to provide similar opportunities.

\section{Limitations}

This study is subject to several limitations. First, there was insufficient response from the planned control group, which limited our ability to determine conclusively that the improvements observed were derived solely from the intervention. The limited size of the NHLBI contract precluded extensive attempts to recruit additional control participants. Second, our sample was limited to one state, and regional differences in asthma care may affect this intervention in other settings. Although the facilitating faculty used an agreed-upon curriculum for conducting group SAMs, each state's Academy chapter managed the recruitment and retention of participants differently. This heterogeneity led to optimal completion of the exercise among only the Virginia participants. In addition, the chart abstraction data represent self-reported results, which may be subject to reporting error. The contract did not have a budget for audit and validation of the reports; however, prior work has shown that physicians reliably and accurately abstract data when participating in MOC activities, which somewhat limits this concern. ${ }^{28}$ Also, only $34 \%$ of group SAM participants in Virginia elected to participate in the full study. This could introduce bias since these physicians may be more motivated to improve the quality of care they provide and may differ from other participants in other ways. Finally, we assessed care 6 months after the intervention; longer-term assessment of patient care may be needed to demonstrate sustained adherence to the guidelines.

\section{Conclusion}

Our study found that group self-assessment activities based on asthma can serve as an effective means of disseminating new guidelines and promoting guideline adherence in clinical practice. We observed significant improvements in key asthma 
guideline measures that have particular importance in primary care. The magnitude of the improvements suggests a substantial real impact of the intervention, despite the absence of a sufficient comparison group. In addition, these changes were largely sustained 6 months following the intervention.

A number of organizations have organized group activities to facilitate family physicians' completion of their MOC requirements (eg, the Mayo Clinic, ${ }^{29}$ the American Academy of Family Physicians, ${ }^{30}$ and the Virginia Academy of Family Physicians ${ }^{31}$ ). We are unaware of literature reports published to date regarding the outcomes of these activities. However, information in the literature suggests that use of facilitators can indeed improve the uptake of clinical guideline recommendations. ${ }^{32-34}$ Our study similarly suggests—although it is subject to limitations-that a facilitated group SAM process represents a viable vehicle for promoting guideline recommendations and improving the quality of care that family physicians deliver.

We recognize the Virginia Academy of Family Physicians for their outstanding and consistent support in the original development of the group SAM used for this study.

\section{References}

1. Follenweider LM, Lambertino A. Epidemiology of asthma in the United States. Nurs Clin North Am 2013;48:1-10.

2. Breekveldt-Postma NS, Erkens JA, Aalbers R, van de Ven MJ, Lammers JW, Herings RM. Extent of uncontrolled disease and associated medical costs in severe asthma-a PHARMO study. Curr Med Res Opin 2008;24:975-83.

3. Guidelines for the diagnosis and management of asthma (EPR-3). Bethesda, MD: National Heart, Lung, and Blood Institute, National Institutes of Health; 2007. Available from: https://www.nhlbi. nih.gov/guidelines/asthma/. Accessed March 6, 2014.

4. Expert Panel report 2: guidelines for the diagnosis and management of asthma. Bethesda, MD: National Heart, Lung, and Blood Institute, National Institutes of Health; 1997. Available from: http:// www.nhlbi.nih.gov/guidelines/archives/epr-2/. Accessed March 6, 2014.

5. Expert Panel report: guidelines for the diagnosis and management of asthma - update on selected topics 2002. Bethesda, MD: National Heart, Lung, and Blood Institute, National Institutes of Health; 2003. Available from: https://www.nhlbi.nih.gov/guidelines/archives/ epr-2_upd/index.htm. Accessed March 6, 2014.
6. Cabana MD, Rand CS, Powe NR, et al. Why don't physicians follow clinical practice guidelines? A framework for improvement. JAMA 1999;282: $1458-65$.

7. Grant EN, Malone A, Lyttle CS, Weiss KB. Asthma morbidity and treatment in the Chicago metropolitan area: one decade after national guidelines. Ann Allergy Asthma Immunol 2005;95:19-25.

8. Wisnivesky JP, Lorenzo J, Lyn-Cook R, et al. Barriers to adherence to asthma management guidelines among inner-city primary care providers. Ann Allergy Asthma Immunol 2008;101:264-70.

9. Halterman JS, Aligne CA, Auinger P, McBride JT, Szilagyi PG. Inadequate therapy for asthma among children in the United States. Pediatrics 2000;105: 272-6.

10. Cabana MD, Bruckman D, Meister K, Bradley JF, Clark N. Documentation of asthma severity in pediatric outpatient clinics. Clin Pediatr (Phila) 2003; 42:121-5.

11. Cabana MD, Slish KK, Nan B, Lin X, Clark NM. Asking the correct questions to assess asthma symptoms. Clin Pediatr (Phila) 2005;44:319-25.

12. Halterman JS, Yoos HL, Kaczorowski JM, et al. Providers underestimate symptom severity among urban children with asthma. Arch Pediatr Adolesc Med 2002;156:141-6.

13. Mazurek JM, Schleiff PL. Physician recognition of work-related asthma among US farm operators. Fam Med 2010;42:408-13.

14. Akinbami LJ, Moorman JE, Garbe PL, Sondik EJ. Status of childhood asthma in the United States, 1980-2007. Pediatrics 2009;123(Suppl 3):S131-45.

15. Flores G, Snowden-Bridon C, Torres S, et al. Urban minority children with asthma: substantial morbidity, compromised quality and access to specialists, and the importance of poverty and specialty care. J Asthma 2009;46:392-8.

16. Ortega AN, Gergen PJ, Paltiel AD, Bauchner H, Belanger KD, Leaderer BP. Impact of site of care, race, and Hispanic ethnicity on medication use for childhood asthma. Pediatrics 2002;109:E1.

17. Asthma care quality improvement. A resource guide for state action. Rockville, MD: Agency for Healthcare Research and Quality (AHRQ); 2009. Available from: http://www.ahrq.gov/legacy/qual/asthmacare/. Accessed August 6, 2013.

18. National Asthma Control Initiative. Putting guideline priorities into action. Updated January 2013. Available from: https://www.nhlbi.nih.gov/health/ prof/lung/asthma/naci/discover/priorities.htm. Accessed March 6, 2014.

19. National Asthma Control Initiative. Discover the NACI. Updated December 2012. Available from: http://www.nhlbi.nih.gov/health/prof/lung/asthma/ naci/discover/. Accessed February 4, 2014.

20. Hagen MD, Ivins DJ, Puffer JC, et al. Maintenance of certification for family physicians (MC-FP) self 
assessment modules (SAMs): the first year. J Am Board Fam Med 2006;19:398-403.

21. Sumner W 2nd, O'Neill TR, Roussel G, et al. Family physicians' completion of scoring criteria in Virtual Patient encounters. AMIA Annu Symp Proc 2011;2011:1355-60.

22. NACI Strategic Partnership Program. Updated December 2013. Available from: http://www.nhlbi. nih.gov/health/prof/lung/asthma/naci/naci-in-action/ partners.htm. Accessed February 4, 2014.

23. Liu B, Donovan B, Hocking JS, Knox J, Silver B, Guy R. Improving adherence to guidelines for the diagnosis and management of pelvic inflammatory disease: a systematic review. Infect Dis Obstet Gynecol 2012;2012:325108.

24. Culley DJ, Sun H, Harman AE, Warner DO. Perceived value of Board certification and the Maintenance of Certification in Anesthesiology Program (MOCA®). J Clin Anesth 2013;25:12-9.

25. Goldman L GA, Kessler B. Do not enroll in the current MOC program. N Engl J Med 2010;362:950-2.

26. O'Neill TR, Puffer JC. Maintenance of Certification and its association with the clinical knowledge of family physicians. Acad Med 2013;88:780-7.

27. Sumner W, O’Neill TR, Owens PL, Schootman M, Hagen M. ABFM Examination asthma item performance and asthma prevention quality indicators in Kentucky. J Kentucky Med Assoc 2012;110:7-10.

28. Duffy FD, Lynn LA, Didura H, et al. Self-assessment of practice performance: development of the
ABIM Practice Improvement Module (PIM). J Contin Educ Health Prof 2008;28:38-46.

29. Hot topics in neurology and neurologic surgery for the primary clinician. Self-Assessment Module. Available from: http://www.mayo.edu/cme/ neurology-and-neurologic-surgery-2013r827/sectionID/ B900DCC0-7239-11E2-964D0050569C0CB4/ subsectionID/FAED6DF0-723A-11E2-964D0050569 C0CB4. Accessed February 4, 2014.

30. Self-Assessment Module (SAM) working groups. Leawood, KS: American Academy of Family Physicians; 2014. Available at http://www.aafp.org/cme/ cme-topic/sams.html. Accessed February 4, 2014.

31. 2013 VAFP Self Assessment Module (SAM) group learning. Richmond: Virginia Academy of Family Physicians; 2013. Available at http://vafp.org/wp-content/ uploads/2013/02/2013_SAM_Learning_Session_ Calendar.pdf. Accessed February 4, 2014.

32. Burke JP, Gitlin LN. How do we change practice when we have the evidence? Am J Occup Ther 2012; 66:e85-8.

33. Quintanilha M, Downs S, Lieffers J, Berry T, Farmer A, McCargar LJ. Factors and barriers associated with early adoption of nutrition guidelines in Alberta, Canada. J Nutr Educ Behav 2013;45:510-7.

34. Bigham BL, Aufderheide TP, Davis DP, et al. Knowledge translation in emergency medical services: a qualitative survey of barriers to guideline implementation. Resuscitation 2010;81:836-40. 